\title{
REFLEXÕES INICIAIS SOBRE O EROTISMO EM KAFKA Aं BEIRA-MAR, DE HARUKI MURAKAMI
}

\author{
Michele Eduarda Brasil de Sä
}

RESUMO: Este artigo apresenta um esforço preliminar de pesquisa sobre o erotismo no romance Kafka à beira-mar do escritor japonês Haruki Murakami. Partindo do pressuposto de que haja uma diferença conceitual entre erotismo e sensualismo na literatura japonesa, busca compreender como ambos se materializam na obra pesquisada. Por fim, reflete sobre a função do erotismo na obra e sobre os perigos de uma interpretação orientalista, que acabe por atrapalhar mais do que auxiliar a leitura do texto. São apresentados alguns excertos do romance a fim de ilustrar as colocações ao longo do artigo. Ninomiya (1999), Paz (1994) e Bataille (1987) servem de fundamentação teórica para as reflexões realizadas.

PALAVRAS-CHAVE: Erotismo; Haruki Murakami; Literatura Japonesa Contemporânea.

\section{Introdução}

Há algum tempo, participei de uma mesa redonda sobre erotismo em obras literárias orientais e eslavas. Representando a literatura japonesa, preparei-me para falar um pouco sobre o que estava estudando no romance Kafka à beira-mar, de Haruki Murakami, que eu pesquisava na época; ao lado, outras colegas falariam também de suas pesquisas, cada qual na sua área (literatura russa, hebraica, árabe). A pessoa que nos apresentou, como de praxe, indicou a filiação de cada uma de nós e fez um breve comentário sobre os títulos de nossas apresentações. Para minha surpresa, porém, ao dizer o título da minha participação - o mesmo que dou a este capítulo - fez o seguinte comentário: “em literatura japonesa não se fala sobre erotismo, mas sobre sensualismo". O que veio em seguida foram exemplos como os poemas clássicos e a literatura de Kawabata Yasunari para demonstrar que a literatura japonesa nesse aspecto apenas sugere, faz imaginar, mas não explicita, não descreve. Eu pensava nos trechos que tinha separado para apresentar, que eram bastante explícitos - e eu nem tinha selecionado os mais picantes. Apresentei-os, enfim, e confesso que fiquei satisfeita ao perceber que muitos na audiência já conheciam o romance de Murakami. O debate foi bom e, quando é assim, nós levamos conosco para casa algumas perguntas, que, por sua vez, gerarão outras.

Uma das perguntas que trouxe comigo surgiu naquele comentário inicial. Não foi verbalizada no momento da apresentação, mas ressoava aqui dentro: que distinção há, teoricamente falando, entre erotismo e sensualismo - de forma geral e de forma específica, ou seja,

\footnotetext{
* Doutora em Letras (Letras Clássicas) pela Universidade Federal do Rio de Janeiro (UFRJ). Professora da UFRJ. Atualmente em exercício provisório na Universidade Federal de Mato Grosso do Sul (UFMS).
} 
no âmbito exclusivo da literatura japonesa? Este devia ser meu ponto de partida, por mais elementar que parecesse. Admitir que em literatura japonesa não se fala sobre um determinado aspecto parecia-me algo absurdo, já que é impossível alguém conhecer tudo sobre toda a literatura japonesa (afinal de contas, é uma literatura milenar, em um país insular, de certa forma fragmentada nas ilhas que o compõem), especialmente porque este "toda" muitas vezes se restringe ao cânone. E nem era o caso de tratar de literatura erótica como gênero (este, então, para lá da margem), mas sim do erotismo em uma dada obra literária.

Por falar em cânone, já houve quem considerasse a literatura de Murakami apenas uma manifestação frívola de resposta ao mercado. Um dos mais conhecidos foi o ganhador do Nobel de Literatura Kenzaburo Oe, que até reconhecia o talento de Murakami, porém o criticava por considerar suas obras "uma resposta que beira a adulação de seus jovens leitores". Talvez ainda haja quem pense assim, especialmente os que, como fazia Oe há mais de vinte anos, abraçam o conceito de junbungaku ("literatura pura", "sincera") como o oposto de popular. Mas isto não vem ao caso, a não ser pelo simples fato de Murakami ser frequentemente julgado e condenado por usar - e, na perspectiva de alguns críticos, abusar - de elementos da cultura pop em seus livros. De minha parte, preciso confessar que o que ouvi com tom negativo a respeito de sua obra (que era difícil, que era "sem pé nem cabeça", que tinha muitos elementos "ocidentais") foi o que soou positivo para mim e atiçou a minha curiosidade, levando-me a escolher um de seus romances para transformá-lo em objeto de pesquisa.

\section{Um Édipo à beira-mar}

Um jovem de quinze anos chamado Kafka Tamura resolve sair de casa no dia de seu aniversário. Vive com o pai, com quem mal se relaciona; sente falta da mãe e da irmã, que partiram quando ele era muito novo. Já no capítulo um, sendo apresentado este contexto, percebe-se que vem por aí um diálogo com Édipo - tanto a tragédia em si quanto as leituras que dela são feitas a posteriori, na Psicanálise, por exemplo. Em paralelo, narra-se a história de Satoru Nakata, um senhor já com cerca de sessenta anos, que fala com gatos e vive de encontrar felinos perdidos para seus donos. É tratado como um pária por causa de um incidente que teve na infância, que fez dele uma pessoa com capacidade intelectual restrita, embora ele antes fosse uma criança brilhante. O nome Satoru remete à palavra satori, uma "iluminação", um momento de "expansão da consciência", em que se descobre algo relevante

\footnotetext{
1 “[...] a response bordering on adulation in their young readers" (OE, 1995. p. 50). Oe se refere às obras de Haruki Murakami e Banana Yoshimoto, campeões de vendas na época.
} 
para a vida, mas ele fala e age como alguém que não amadureceu. Neste aspecto, é como se Kafka e Nakata se opusessem, mas não como quem vem de pontos contrários a se encontrarem no meio do caminho, e sim como se percorressem a mesma linha, cada um em uma face de um espelho.

Kafka é ajudado por Sakura, uma jovem um pouco mais velha, em quem ele tenta encontrar uma imagem da irmã que nunca mais tinha visto. Seguindo sua viagem, Kafka é acolhido em uma biblioteca, onde passa a morar, alojando-se em um pequeno quarto; neste lugar, a Biblioteca Komura, tinha vivido o namorado da Sra. Saeki, a diretora da biblioteca. Seu namorado tinha morrido muito jovem e ela nunca mais conseguiu se relacionar com ninguém. Kafka se apaixona por ela ao mesmo tempo em que se pergunta se ela não poderia ser sua mãe; ela, por sua vez, se apaixona por ele e se entrega.

Nesse meio tempo, em busca de mais um gato perdido, Nakata é atraído até uma mansão, onde ele conhece Johnny Walker e descobre que era ele quem matava os gatos. Nakata, instigado pelo próprio Johnny Walker, mata-o; em seguida, Kafka, distante de casa, vem a saber da notícia do assassinato de seu pai, o escultor famoso Koichi Tamura. Kafka pensa se não foi ele mesmo que matou o pai, pois não tinha explicação para ter acordado em um templo xintoísta, com uma mancha de sangue na camisa, sem compreender como foi parar ali naquelas condições.

O ímpeto de matar o pai, o desejo de possuir a mãe (e, no caso deste romance, a irmã), a impossibilidade de fugir de um destino que predetermina todas as coisas, na existência da profecia - o "mecanismo embutido em mim" (p. 16) - são elementos que desde o primeiro capítulo nos remetem à tragédia de Édipo. Não se deve, porém, limitar este romance a uma leitura intertextual com este mito apenas. Murakami dialoga com várias outras obras ("A metamorfose" e "Carta ao pai” de Franz Kafka são também evidentes), inclusive da literatura japonesa (alguns exemplos são “A história de Genji”, de Murasaki Shikibu, o conto "O mineiro”, de Natsume Soseki). Trata-se de uma obra riquíssima e, ao mesmo tempo, desafiadora e enigmática, como a esfinge do mito.

O quadro na parede do quarto na biblioteca, com a mesma cena cantada na letra da música que a Sra. Saeki tinha gravado quando jovem, mostra um garoto de uns doze anos sentado em uma cadeira, mão apoiando o rosto, à beira-mar. O próprio Kafka Tamura, observando o quadro, pensa se o jovem pintado não teria sido o rapaz que a Sra. Saeki amava. No quadro e na música percebemos que há entrecruzamentos no tempo e no espaço, ligando Kafka à Saeki jovem, Kafka à sua mãe, Saeki ao seu amado. É como se a imagem pintada/cantada pusesse ordem no caos, como se a imaginação interferisse diretamente na 
realidade. Embora o limite entre imaginação e realidade seja algo mal definido, talvez móvel, como o ir e vir das ondas, o fato é que Kafka e Saeki se relacionam sexualmente mais de uma vez. Neste sentido, Kafka só se torna Édipo - e o supera - à beira-mar.

\section{Definição, definições: uma busca insaciável}

A refletir sobre erotismo - e, então, sobre sensualismo - o primeiro passo é buscar elementos teóricos que norteiem o estudo, começando por definições. Segundo Ninomiya (1999, p. 101), “mesmo na literatura moderna é difícil manter estanques os conceitos de erotismo e sensualismo"; prosseguindo, diz que "erotismo se liga ao princípio da ação e sensualismo ao princípio da sensibilidade" (loc. cit.). Interpreto da seguinte forma: o erotismo diz respeito ao que é descrito, desnudado, exposto, narrado enquanto ato, daí o "princípio da ação". O sensualismo, por sua vez, diz respeito ao que é sugerido, ou mostrado em parte, transformado em imagem que seduz, daí o "princípio da sensibilidade". Se a leitura que faço está correta, então temos exemplos de um e outro na obra, dentre os quais destaco os seguintes:

[...] A guia, Sra. Saeki, tem cerca de 45 anos e é magra. É também alta em comparação às demais mulheres da sua geração. Usa vestido verde com um cardigã creme claro jogado sobre os ombros. Seu porte é elegante. Seus cabelos, longos, estão arrebanhados frouxamente na nuca. O rosto é delicado e inteligente. Tem olhos bonitos. E também um sorriso suave como uma sombra brincando sempre em seus lábios. Um sorriso que não sei descrever direito, mas que me parece conclusivo. Lembra uma pequena e ensolarada poça de luz, de formato único e que só se encontra em lugares secretos. No jardim de minha casa em Nogata, havia um cantinho e uma poça semelhantes, e desde muito pequeno sempre os amei. A Sra. Saeki desperta em mim uma sensação forte, mas, ao mesmo tempo, de comovente nostalgia. (KBM, p. 52-53) - sensualismo

Ela enterra o rosto em seu peito. Você sente contra a pele nua a respiração dela. Ela segue com a ponta dos dedos o traçado de cada um dos seus músculos. Depois, lambe carinhosamente seu pênis avermelhado, tentando confortá-lo. Você goza. Ela deglute o sêmen como se este fosse algo muito precioso. Você beija a genitália dela. A ponta da sua língua toca todos os recantos dela. É então que você se transforma em outra pessoa e em outra coisa. Está em outro lugar. (KBM, p. 391) - erotismo

Na primeira passagem, temos a descrição de como Kafka Tamura vê a Sra. Saeki, tendo acabado de conhecê-la. A sua imagem não tem nada de vulgar, o porte é "elegante", típico de uma discreta senhora de meia idade que dirige uma biblioteca. É justamente esta imagem, em uma referência quase maternal, que atrai o jovem. Ele observa os cabelos, a nuca, o rosto, os olhos e o sorriso, onde se detém mais um pouco, sob a força das reminiscências. O sensualismo aqui encontrado emaranha-se com o sentimento edipiano do protagonista. 
Já na segunda passagem, a cena descrita contém detalhes explícitos. Descreve-se a ação, não a imagem. A "sensação forte" que a Sra. Saeki provocava em Kafka Tamura no início agora transborda e deságua no ato sexual. A primeira passagem é essencialmente adjetival, ao passo que a segunda é primordialmente verbal.

Apresento a seguir outras duas passagens que podem também ilustrar a distinção que se pretende fazer. Desta vez, a referência materna ("líquido amniótico") encontra-se no excerto que ilustra o erotismo:

\begin{abstract}
Eu continuo na cadeira por algum tempo e contemplo as costas da Sra. Saeki. Os movimentos do seu corpo, o jeito como anda. Todos os seus gestos me parecem extremamente naturais e elegantes. Não consigo me expressar direito, mas sinto neles algo especial. Sinto que suas costas tentam me dizer alguma coisa. Algo que não pode ser transformado em palavras. Mas não sei o que é esse algo. Aliás, existem muitas coisas que não sei. (KBM, p. 82) - sensualismo
\end{abstract}

O sonho dela engloba sua consciência num piscar de olhos. Cálido e suave, como líquido amniótico. A Sra. Saeki remove sua camiseta e sua cueca. Beija-o diversas vezes no pescoço, estende a mão e segura seu pênis que, ao contrário dos gestos dela, está rígido como porcelana. Com a mão, ela envolve seu escroto. E sem nada dizer, leva sua mão para os pêlos púbicos dela. A genitália está quente e úmida. Ela beija seu tórax. Suga-lhe o mamilo. Seus dedos penetram dentro dela, lentamente, como que atraídos por força invisível. (KBM, p. 342) - erotismo

Feita esta distinção (ou antes esboçada a sua tentativa), devo retornar ao foco da pesquisa, que é o erotismo. Acho particularmente belas as palavras de Octavio Paz (1994, p. 12), quando ele relaciona erotismo e poesia, dizendo que "o primeiro é uma poética corporal e a segunda é uma erótica verbal". Diz ele que o erotismo "é sexualidade transfigurada: metáfora", uma "metáfora da sexualidade animal" (loc. cit.). Prosseguindo na busca de um conceito ou definição que pudesse me ajudar, recorri à obra $O$ erotismo, de Georges Bataille. Ambos, Bataille e Paz, referem que o erotismo é humano, em oposição à sexualidade, que é animal, e faz diferença esclarecer isto de início para não confundir o sensualismo mencionado aqui anteriormente com a sexualidade, um atributo de caráter biológico e natural, presente no homem enquanto animal.

$\mathrm{Na}$ introdução, Bataille (1987, p. 10) já começa dizendo o seguinte: "Do erotismo é possível dizer que ele é a aprovação da vida até na morte. Para falar a verdade, isto não é uma definição, mas eu penso que esta fórmula dá o sentido do erotismo melhor que uma outra". Mais adiante ele desenvolve esta ideia, explicando o erotismo como uma forma de manifestar o desejo de continuidade. Diz ainda que "somos seres descontínuos, indivíduos que morrem isoladamente numa aventura ininteligível, mas temos a nostalgia da continuidade perdida" (Ibid., p. 12).

Kafka e Saeki têm cada qual a sua sensação de falta; ele está preso no "labirinto do tempo"; ela, ao amor interrompido no passado. Um busca suprir no outro esta falta, saciar 
este desejo de continuidade. Por esta razão, não se pode dizer que o erotismo presente em determinados momentos da narrativa seja gratuito; ele tem um motivo, ou antes uma explicação. É na relação erótica que Saeki reencontra seu namorado e Kafka, sua mãe, em uma perspectiva edipiana - e ambos se completam.

A estranheza que esta equação nos causa repousa no fato de que, segundo Bataille (1987, p.165), “a sexualidade humana é limitada pelos interditos, cuja transgressão pertence ao campo do erotismo. O desejo do erotismo é o desejo que triunfa do interdito.” O incesto é claramente um interdito, mas não é o único. O jovem Kafka Tamura tem quinze anos quando do início de sua jornada pessoal; ainda está conhecendo seu próprio corpo, questionando, imaginando, fantasiando. No mesmo tempo em que tem curiosidade, em que busca compreender e saciar o desejo que lhe surge de forma natural, de matriz biológica, Kafka sente estranheza e culpa - esta última estreitamente ligada à questão do interdito, que Bataille apresenta em seu livro. Cito dois trechos para exemplificar o que digo:

Retorno à cabana e me enxugo com uma toalha. Sento-me na cama e observo
meu pênis. Um pênis sadio, de coloração clara, recém-liberto do prepúcio. Depois
do banho de chuva, a glande ainda arde um pouco. Contemplo longamente esse
estranho órgão que, apesar de me pertencer, quase nunca obedece à minha von-
tade. Sinto como se ele ruminasse pensamentos diferentes daqueles que habitam
o meu cérebro.
[...] Estendo a mão e penso em me masturbar. Reconsidero e desisto. Quero pre-
servar por mais algum tempo esta misteriosa sensação de pureza que me restou
depois do violento banho de chuva. (KBM, p. 171)
Logo, uma vaga sensação de languidez se espalha pelos quadris. Como se eu flu-
tuasse em líquido denso. Digo isso, e ela apanha um lenço de papel que tem à
cabeceira e me leva a ejacular. E eu ejaculo com força, muitas e muitas vezes.
Pouco depois, ela vai para a cozinha, joga o lenço de papel no lixo e lava as mãos.
- Desculpe - digo.
- Ora, que é isso! - replica a caminho da cama. - Não se desculpe de maneira
tão formal que me deixa constrangida. É apenas uma função física, não se preo-
cupe com bobagens. Mas aposto que está se sentindo aliviado, não está? (KBM,
p. 117)

No primeiro trecho, Kafka encontra-se sozinho, na cabana na floresta, onde se refugiou após a divulgação do assassinato de seu pai na imprensa. Trata-se de um momento de profundas transformações para o jovem, sendo a própria floresta um espaço em que realidade e sonho se misturam. Tudo é muito confuso e inevitável, como a manifestação do seu desejo. No segundo trecho, Kafka está no apartamento de Sakura, a jovem que ele conheceu no ônibus ao deixar a cidade e que ele às vezes pensava se não poderia ser sua irmã. Ela o acolhe naquela noite depois que ele lhe telefonou nervoso, por ter acordado sujo de sangue em um templo xintoísta, sem nada compreender - nem o fato de estar naquele lugar, que sequer conhecia. Sakura permite inclusive que ele se deite com ela, embora dizendo que 
apenas dormiriam (“como irmãos”), porque ela já tinha namorado. Kafka acaba tendo uma ereção e ela o ajuda a se aliviar. É curioso que, logo após, Sakura confessa a Kafka que acha que seria bom se ela fosse sua irmã de verdade.

Para Kafka Tamura, Sakura de alguma forma representa o elo com a realidade. Ele lhe diz: "Não consigo explicar direito, mas você, Sakura, vive num mundo real, respira o ar real e fala coisas reais. Quando converso com você, sinto-me perfeitamente conectado com a realidade” (KBM, p. 339). Com Saeki, a sensação é diferente: além de mais intensa, ela é mais frequente e transita entre o sonho e a realidade, entre o presente e o passado.

Em seu livro "A dupla chama”, sobre o amor e o erotismo, Paz (1994, p. 99) diz que “o amor filial, fraternal, paternal e maternal não são amor: são piedade”, esclarecendo o caráter religioso que esta palavra carrega. Trata-se de um sentimento que tem por esteio uma devoção herdada, uma ideia de pertencimento a ser venerada, tão sacra e espiritual que não se pode contaminar com o carnal. Daí que, como ele mesmo diz, o incesto quase nunca é voluntário (Ibid., p.98). O duplo incesto em Kafka à beira-mar, no entanto, mostra-se uma espécie de necessidade mística para trazer ordem ao caos, uma determinação do destino, o cumprimento de uma profecia. Sendo assim, de alguma forma se enfraquece o seu caráter transgressor. Não se pode ignorar, porém, que não se trata de incestos propriamente ditos, porque de fato nem Sakura é irmã de Kafka, nem Saeki é sua mãe. Visto dessa maneira, há que se repensar a extensão do interdito nas relações entre estes personagens.

\section{Para além de Kafka, Saeki e Sakura}

O capítulo 12 do romance Kafka à beira-mar é uma carta da professora de Nakata a um sensei (cujo nome não é mencionado), confessando o que tinha acontecido de verdade no dia do incidente do coma coletivo no bosque, do qual todas as crianças se recuperaram, exceto Nakata. ${ }^{2}$ Em dado momento, a professora assim se expressa, deixando claro o seu sentimento de culpa:

\footnotetext{
Mandei as crianças descansarem um pouco e, embrenhando-me no bosque, adotei medidas emergenciais com a ajuda de algumas toalhas de mão que trouxera comigo. A hemorragia era considerável, e eu me apavorei momentaneamente, mas imaginei que as toalhas dariam conta do recado até o momento de retornarmos à escola. Minha mente estava anuviada e eu não conseguia raciocinar direito. Acredito também que experimentava uma leve sensação de culpa. Pelo sonho de teor escandaloso, por me ter masturbado e por me ter perdido em devaneios eróticos na presença das crianças. Eu era do tipo reprimido. (KBM, p. 136-137)
}

\footnotetext{
${ }^{2}$ Este sensei ("professor", em japonês, mas que também designa alguém mais experiente) parece referir-se a algum superior, um coordenador ou diretor da escola, por exemplo.
} 
O que aconteceu foi que Nakata tinha encontrado uma das toalhas com o sangue e veio entregá-la à professora. Constrangida e nervosa, ela acabou agredindo fisicamente o menino na frente das outras crianças, dando-lhe vários tapas no rosto. Ele e as demais crianças da turma ficaram em estado de choque diante da reação da professora. Mesmo a professora abraçando-o e pedindo desculpas, ele não voltou ao normal. Logo após ocorreu o incidente, as crianças passaram pelo inexplicável coma e apenas Nakata demorou mais tempo para se recuperar, com sequelas.

É inusitado o capítulo, mas ele é construído como uma confissão: a professora acredita que é sua culpa o fato de Nakata ter sofrido daquela forma. Ela o considerava um menino antes tão desenvolvido, tão responsável, embora ela se preocupasse com as reações que ele tinha por vezes, como se estivesse sempre com medo. A raiz do problema, para ela, estava no sonho erótico que ela teve com o marido (que estava longe, por causa da guerra) na noite anterior; o sonho parecia tão real que ela ainda sentia toda aquela volúpia enquanto guiava as crianças no bosque. Foi quando ela percebeu que menstruava. Se não tivesse tido aquele sonho, não se encontraria naquele estado pela manhã, não menstruaria, não precisaria descartar as toalhas improvisadas, Nakata não as veria... Tudo partia do sonho - este espaço onde a realidade é trabalhada e onde o erotismo anda livre.

De fato, é neste turbilhão que Nakata vê modificado seu rumo. O que isso pode querer dizer? É uma pergunta para a qual não tenho uma resposta satisfatória ainda. Penso neste episódio tentando relacionar as personagens professora de Nakata e Saeki, ambas separadas muito cedo de seus amores. Perdidos os parceiros, elas vivem perdidas também. Bataille (1987, p. 21) diz que "no erotismo, EU me perco. Não é, sem dúvida, uma situação privilegiada. Mas a perda voluntária implicada no erotismo é flagrante.” A entrega mútua advém desta perda voluntária. Eis porque ele, ao mencionar Hegel, diz que "o erotismo não pode ser abordado senão dialeticamente" (Ibid., p. 164). Isso nos leva a outra passagem inusitada do romance: as palavras da prostituta que o Coronel Saunders traz para Hoshino, jovem motorista que conhece Nakata e o acompanha a partir de determinado momento:

\footnotetext{
— Bem, assim de repente não me ocorre nenhum pedido especial, mas que acha de citar mais alguma coisa do tipo filosófico? Não entendo nada, mas talvez sirva para retardar a ejaculação. Do jeito que vai, não vou conseguir segurar por muito tempo...

— Vejamos então... É um tanto antigo, mas que acha de Hegel?

- Serve, serve. O que você quiser.

— Pois recomendo Hegel. Antiquado, mas... Tá-rá!, aqui vai um dos oldies but goodies!

- Ótimo.

— "O eu é o conteúdo da relação e a relação mesma."

- Ahn...!

- Hegel estabeleceu a chamada "consciência-de-si" e diz que o sujeito humano não só tem conhecimento de si mesmo e do objeto separadamente, como também
} 
melhor se compreende pela projeção de si sobre o objeto como mediador. Isto é consciência-de-si.

— Não entendi nada.

- Em outras palavras, é o que estou fazendo com você neste momento. Para mim, eu sou o "si" e você é o objeto. Para você, é naturalmente o contrário: você é o "si" e eu sou o objeto. Neste momento, estamos realizando uma permuta de "si" e do "objeto" e assim estabelecendo a "consciência-de-si". Ativamente.

- Continuo não compreendendo, mas me sinto consolado.

— É o que interessa — disse ela. (KBM, p. 297)

Esta consciência-de-si de Hegel é encontrada na metáfora do senhor e do escravo; grosso modo, o senhor só é senhor porque, além de reconhecer-se assim, existe o escravo, que também o reconhece. O mesmo vale no sentido inverso: o escravo só é escravo porque ambos (senhor e escravo) assim o consideram. Uma prostituta explicar Hegel no momento do ato sexual é algo inusitado demais para ser gratuito; Murakami apresenta, em uma relação erótica, o cerne dela mesma: a dialética.

\section{Considerações finais: o desejado intangível}

Pensar sobre o erotismo e as questões relacionadas a ele não é frivolidade, de forma alguma. Como diz Bataille (1987, p. 175), "Enquanto é animal erótico, o homem é para si mesmo um problema. O erotismo é em nós a parte problemática. [...] Entre todos os problemas, o erotismo é o mais misterioso, o mais geral, o mais à distância”.

Estas reflexões são, como o título indica, apenas iniciais; trata-se de um romance longo, com muitos personagens que merecem atenção neste aspecto. Busco ainda um aporte teórico que apresente circunstâncias e elementos específicos pelos quais o erotismo possa ser estudado sob o olhar da cultura japonesa. O fato de ter recorrido apenas a obras teóricas cujos autores são ocidentais me faz pensar se perspectivas semelhantes seriam apresentadas por autores japoneses. Por outro lado, é preciso ter cuidado com abordagens orientalistas: elas pairam mesmo sobre obras de teóricos como Foucault (1978, p. 57-58), por exemplo, que associa nações orientais ( o Japão obviamente incluído) à elaboração cada qual de uma ars erotica e a "civilização ocidental" a uma scientia sexualis. A própria caracterização da literatura japonesa como uma literatura do sensualismo, em que o erotismo não encontra espaço, parece uma visão impregnada de orientalismo, entendido como uma interpretação distante, que tende a transformar em exótico o que muitas vezes é natural, embora típico de uma perspectiva diversa.

À parte todo este cuidado, é preciso ter em mente também que Haruki Murakami de modo algum se limita a um paradigma de literatura japonesa (pura ou $p \circ p$ ), cosmopolita que 
é. Desta forma, tanto mais misterioso, geral e à distância vai ficando o nosso tema - ou antes o nosso problema.

\section{INITIAL REFLECTIONS ON EROTICISM IN KAFKA ON THE SHORE, BY HARUKI MURAKAMI}

ABSTRACT: This article presents a preliminary research effort on eroticism in the novel Kafka on the Shore by Japanese writer Haruki Murakami. Based on the assumption that there is a conceptual difference between eroticism and sensualism in Japanese literature, this paper seeks to understand how both materialize in the researched work. Finally, it reflects on the role of eroticism in the novel and on the dangers of an orientalist interpretation, which ends up hindering more than helping to read the text. Some excerpts of the novel are presented in order to illustrate the assertions along the article.. Ninomiya (1999), Paz (1994) and Bataille (1987) serve as theoretical foundation for the reflections conducted.

KEYWORDS: Contemporary Japanese Literature; Eroticism; Haruki Murakami.

\section{REFERÊNCIAS}

BATAILLE, Georges. O erotismo. Trad. de Antonio Carlos Viana. Porto Alegre (Brasil): Editora L\&PM, 1987.

FOUCAULT, Michel. The History of Sexuality, vol. 1, Trans. Robert Hurley. New York: Pantheon, 1978.

MURAKAMI, H. Kafka à beira-mar. Trad. de Leiko Gotoda. Rio de Janeiro: Objetiva, 2008.

NINOMIYA, Sônia Regina Longhi. O sensualismo na literatura japonesa. Anais do X Encontro Nacional de Professores Universitários de Lingua, Literatura e Cultura Japonesa. 101-105.

Gráfica UFRJ. Rio de Janeiro (Brasil), 1999.

OE, Kenzaburo. Japan, the ambiguous, and myself: The Nobel Prize Speech and other lectures. Tóquio: Kodansha, 1995.

PAZ, Octavio. A dupla chama. Trad. de Wladyr Dupont. São Paulo: Editora Siciliano, 1994.

Recebido em: 31/08/2020.

Aprovado em: 30/12/2020. 